\title{
Outcome of decompressive craniectomy in comparison to nonsurgical treatment in patients with malignant MCA infarction
}

\author{
Abdolkarim Rahmanian ${ }^{1}$, Babak Seifzadeh ${ }^{1}$, Ali Razmkon ${ }^{1,2^{*}}$, Peyman Petramfar ${ }^{3}$, Juri Kivelev ${ }^{4}$, Ehsan-Ali Alibai ${ }^{1}$ \\ and Juha Hernesniemi ${ }^{4}$
}

\begin{abstract}
Background: Malignant cerebral infarction is a well-recognized disease, comprising 10-15\% of all cases with cerebral infarction and causing herniation and death in $80 \%$ of cases. In this study, we compare the effects of decompressive craniectomy versus conventional medical treatment on mortality rate and functional and neurological outcome in patients with malignant MCA infarction.

Methods: We performed a prospective case-control study on 60 patients younger than 80years of age suffering malignant MCA cerebral infarction. The case group underwent decompressive craniectomy in addition to routine aggressive medical care; while the control group received routine medical treatment. Patient outcome was assessed using Glasgow outcome scale and modified Rankin scale within three months of follow-up. The data were analyzed by SPSS version 16.0 software using Chi Square, One-way ANOVA and Mann-Whitney tests.
\end{abstract}

Results: There were 27 male and 33 female patients with a mean age of 60.6 years (SD $=12.3$ ). Glasgow outcome scale score averaged 2.93 in the surgical versus 1.53 in the medical group; this difference was significant $(p=0.001)$.

Outcome in modified Rankin scale was also significantly lower in the surgical (3.27) versus medical (5.27) group $(p<0.001)$. Surgery could decrease the mortality rate about $47 \%$.

Conclusion: In this study, decompressive craniectomy could decrease mortality rate, and improve neurological and functional outcome, and decrease long-term disability in patients with malignant MCA infarction.

Keywords: Cerebral infarction; Decompressive craniectomy; Middle cerebral artery

\section{Introduction}

Malignant supratentorial infarction of the brain is a well-recognized entity, comprising $10-15 \%$ of all cases with cerebral infarction. It causes severe edema, increased focal and generalized intracranial pressure, and finally results in transtentorial or uncal herniation in approximately $80 \%$ of individuals (Holtkamp et al. 2001; Staykov \& Gupta 2011; van der Worp \& Kappelle 2011). The optimal management of these patients has been always a challenge. Decompressive craniectomy (DC) has been used for many years as an option but not a standard;

\footnotetext{
* Correspondence: ali.razmkon@gmail.com

'Department of Neurosurgery, Shiraz University of Medical Sciences,

Nemazee Hospital, P.O. Box: 71937-11351, Shiraz, Iran

${ }^{2}$ Shiraz Neuroscience Research Center, Shiraz University of Medical Sciences, Shiraz, Iran

Full list of author information is available at the end of the article
}

while many studies have shown its efficacy in decreasing mortality rates from $80 \%$ to $30 \%$ (Aarabi et al. 2006; Spagnuolo et al. 2004).

Following the widespread performance of DC in many centers worldwide, newer concerns have been raised. There is still controversy on optimal timing of the procedure, the effectiveness of the operation in different age groups, and most importantly, the significant increase in the severely disabled population of patients who have been added to the survival (Chen et al. 2007; Foerch et al. 2004; Jüttler et al. 2011; Jüttler et al. 2007). Such increase leads to significant health burden and economic pressure over families and the whole society. Until these controversies have not been resolved, the application of DC may be a challenge for every individual patient.

\section{然}

(c) 2014 Rahmanian et al.; licensee Springer. This is an Open Access article distributed under the terms of the Creative Commons Attribution License (http://creativecommons.org/licenses/by/2.0), which permits unrestricted use, distribution, and reproduction in any medium, provided the original work is properly credited. 
In this study, we compared mortality rates and outcome data in two groups of patients subject to DC or aggressive medical therapy, in population of patients from referral center of Southern Iran with cerebral infarction.

\section{Methods}

We performed a prospective case-control study on patients with massive cerebral infarction of the MCA territory who were admitted consecutivelyto a tertiary center affiliated to Shiraz University of Medical Sciences during 2010 and 2011. Institutional review board and research ethics committee of the Shiraz University of Medical Sciences evaluated and approved the work.

\section{Patient selection}

All consecutive patients with acute presentation of neurologic symptoms, 80 years old or younger, who showed unilateral infarctions of $>50 \%$ MCA territory in brain CT or MRI during the mentioned period of time were included in the study. Indications for surgery included significant midline shift $(>5 \mathrm{~mm}$ ), effacement of basal cisterns and sulci, and the absence of brain herniation. Absent brain stem reflexes was also a contraindication to enrollment. All patients had to be admitted before 48 hours of presentation. Patients with bilateral infarctions, hemorrhagic infarctions or transformations, and any terminal illness or concomitant severe medical disease contraindicating surgery were excluded. Early coma was not a contraindication to enrollment.

A control group included also consecutive patients who were admitted shortly before the routine application of DC in our center. These patients, fulfilled the above-mentioned criteria of study enrollment, but did not undergo surgery. They had received aggressive medical treatment, and were compared with patients from the case group.

\section{Treatment}

All patients in the control group received aggressive standard medical treatment of cerebral infarction. This treatment included admission to the neurocritical care units, optimization of blood pressure, hyperosmolar therapy, and mechanical ventilation and sedation if necessary. In case of deterioration, no surgical management had been considered for the patients.

All patients in the case group received aggressive medical treatment, as outlined above, in the first step. Surgery was planned after "significant deterioration" and not prophylactically. "Significant deterioration" was defined as further decrease in consciousness to somnolence, stupor or early coma, or progressive development of either unilateral or bilateral pupil abnormalities. As stated earlier, patients with fixed neurological deficits and deep long-standing coma were excluded from the study.
The operation consisted of a large fronto-temporoparietal craniectomy associated with subtemporal skull decompression. We used a supine position using a roll under the ipsilateral shoulder to avoid over rotation of the head and jugular venous compression. The head was positioned about $10 \mathrm{~cm}$ above heart level. We rotated a large traumatic fronto-temporo-parietal skin flap. Five to 6 burr holes were made to design a single bone flap measuring an average of $15 \mathrm{~cm}$ in larger diameter. We ensured adequate subtemporal skull decompression to prevent uncal herniation, and remained about $2 \mathrm{~cm}$ lateral to the superior sagittal sinus. We opened the dura making a single big dural flap, with a minimum of $5 \mathrm{~mm}$ away from bone edges. Duraplasty with pericranium or temporalis fascia was performed. Free bone flap was saved in abdominal subcutaneous space. A subcutaneous drain was inserted and kept until 24 hours after surgery. Aggressive medical management was continued postoperatively in neurocritical care unit. ICP monitoring was not routinely used after surgery. A post-operative CT was performed to rule-out hematoma formation, and ensure adequate decompression. Patients were discharged after becoming neurologically stable, occurring at least one week after surgery.

\section{Patient evaluation and follow-up}

Clinical status was evaluated using GCS scores at presentation. Demographic variables, pre-existing medical conditions and details of neurological examination and imaging were all recorded for further analysis. In-hospital complications, especially those related to the surgical procedure, were all recorded. All patients were followed by both the neurologist and neurosurgeon at three months after discharge. When direct patient visit was not possible, we tried to contact the patient or the visitors by phone to record outcome. Outcome data included Glasgow outcome scale (GOS) score and modified Rankin scale (MRS) at three months after discharge. GOS is used routinely in our center; however, for better clarification of the functional abilities of patients especially with GOS scores of 3 and 4, we added the MRS scale, which gives more differentiating data about the functional status of the patients (Quinn et al. 2009).

\section{Statistical analysis}

All data were analyzed using SPSS software version 16.0. Chi-square, one-way ANOVA and Mann-Whitney tests were used to analyze the data.

\section{Results}

\section{Patient characteristics}

From 83 patients with malignant MCA infarction, 60 patients were considered eligible for inclusion into the study; 30 patients in either case or control groups. Mean 
age was $60.6 \pm 12.3$ years (mean \pm standard deviation) in both groups. Male to female ration was 0.82 . Basic preoperative clinical parameters have been presented in Table 1. Statistical analysis shows that there was no significant difference between the two groups; therefore, the groups seem matched and comparable.

GCS score on admission was assessed using both parametric and non-parametric tests. Mean GCSs was 6.4 (range 4-12); and there was no significant difference between two groups $(p=0.29)$.

When assessing lateralization, 39 patients $(65 \%)$ had infarctions at the right MCA territory; while 21 (35\%) patients developed infarctions at the left side. There was again no significant difference between case and control groups ( $p=0.65)$.

In the case group, 18 patients $(60 \%)$ underwent surgery within 24 hours after presentation; while the remaining $40 \%$ underwent surgery in the first 48 hours. Therefore, there was no delayed surgery.

\section{Outcome data}

Table 2 shows a summary of outcome data in both groups. Six patients (20\%) died in the DC group, as compared to 20 patients $(67 \%)$ who died in the control group. Such a difference proved to be significant $(p<0.001)$.

GOS scores at three months follow-up were significantly higher (mean: 2.9 vs. 1.5 in case vs. control groups; respectively; $p=0.001$ ). When using non-parametric MannWhitney test, comparison of ranks proved also significantly different $(p=0.001)$. Figure 1 shows the distribution of different scores in each group.

MRS scale was also available for all patients, and similarly, a significant difference was noted. Mean MRS was 3.3 in the case and 5.3 in the control groups $(p<0.001)$. Nonparametric analysis also showed such a significant result $(p<0.001)$. Figure 2 shows the distribution of different scores in each group.

The most common complication encountered during hospital stay was deep venous thrombosis, which occurred in $8.3 \%$ of patients, with no significant difference in any of the groups. While all patients received low dose heparin or enoxaparine as a prophylaxis, these two patients underwent vena caval filter placement. Two patients also developed wound infectionsand underwent irrigation and debridement of the wound and received IV antibiotics.
Further analysis could not show any significant difference in outcome when assessing age, sex, laterality and complication rate.

\section{Discussion}

Decompressive surgery has not been previously considered an option in management of patients with malignant MCA infarction. After the introduction of this treatment and its beneficial effects on the prognosis of patients with malignant brain swelling after severe head injury, this treatment has been also introduced for ischemic cerebral strokes (Aarabi et al. 2006; Spagnuolo et al. 2004). The rate of performance of DC has increased tremendously in CVA patients following reports on the beneficial effects of this treatment (Raffelsieper et al. 2002; Swiat et al. 2010; Walcott et al. 2011).

The surgical management of patients with malignant MCA infarction remains a challenge. Even after decades, there is no definitive agreement between experts about the question of whether decompressive surgery should be performed in patients with malignant MCA infarction (Schwab et al. 1998). Decompressive hemicraniectomy can relieve the mass effect due to infarcted brain tissue and prevent brain herniation and death. Several studies have shown that decompressive surgery can reduce the mortality rate from 80 to $30 \%$ (Delgado-López et al. 2004; Kakuk et al. 2002; Mellado et al. 2005; Mori et al. 2001; Raffelsieper et al. 2002; Robertson et al. 2004; Swiat et al. 2010; Ziai et al. 2003). There is a significant number of studies in literature with controversial results (Arac et al. 2009; Chen et al. 2007; Foerch et al. 2004; Jüttler et al. 2011; Jüttler et al. 2007). Therefore in this study, we compared the surgical versus non-surgical management of patients with malignant MCA infarctions. There are some important technical points which warrant discussion. The size of the bone flap (Aarabi et al. 2006) must be large enough to allow adequate decompression and prevent pressure at the edges. We considered an average size of $15 \mathrm{~cm}$ for the larger diameter of the flap, and visualized no incarceration of the brain tissue at the edges. We also designed a large duraplasty using a single large flap, extending to an average of $5 \mathrm{~mm}$ from bone edges. Subtemporal skull decompression was also performed adequately to prevent uncal herniation.

Table 1 A summary of demographic, clinical and radiological parameters in study groups

\begin{tabular}{lcccc}
\hline Study group & Case (surgical) & Control (medical) & Total & \multicolumn{1}{c}{ v value } \\
\hline Number of patients & 30 & 30 & 60 & $60.6 \pm 12.3$ \\
Mean age \pm SD (years) & $59.0 \pm 13.5$ & $62.1 \pm 11.0$ & $27-33$ & 0.44 \\
Sex (male-female) & $11-19$ & $16-14$ & 6.4 & 0.15 \\
Mean GCSs on admission & 6.9 & 6.0 & $39-21$ & 0.29 \\
Laterality (right - left) & $18-12$ & $21-9$ & 0.65 \\
\hline
\end{tabular}


Table 2 Analysis of outcome data in the study groups

\begin{tabular}{|c|c|c|c|c|}
\hline Study group & Case (surgical) & Control (medical) & Total & $p$ value \\
\hline Number of patients & 30 & 30 & 60 & \\
\hline Outcome in GCS scale & $2.7 \pm 1.2$ & $1.5 \pm 0.9$ & $2.1 \pm 1.2$ & 0.001 \\
\hline Outcome in MRS scale & $3.3 \pm 1.9$ & $5.3 \pm 1.3$ & $4.3 \pm 1.9$ & $<0.001$ \\
\hline Mortality & $20 \%$ & $67 \%$ & $43 \%$ & $<0.001$ \\
\hline Complications & - & - & - & 0.34 \\
\hline
\end{tabular}

The final outcome measure in our study was mortality showing significant reduction $(47 \%)$ in the surgicallytreated group. The mortality rate was $20 \%$ in DC group versus $67 \%$ in medically-treated group. This is comparable to many other studies which have uniformly showed a reduction in mortality. Early decompressive hemicraniectomy in patients with malignant MCA infarction reduced the mortality rate by $50 \%$ at 1 year compared with best medical treatment in one study (Molina \& Selim 2011). Early decompressive craniectomy has decreased mortality to $10-12 \%$ in some reports as compared with nonsurgical management with over 50\% mortality (Kiphuth et al. 2010; Mellado et al. 2005; Staykov \& Gupta 2011; Yang et al. 2005).Our results support previous findings that survival may be better after surgery.

The main challenge is whether the survived patients can return to normal functional life. Some reports have questioned the benefits of decompressive surgery on long-term survival and functional outcome, especially in older patients. Quality of life after hemicraniectomy is one of the most important factors in the choice of treatment for malignant MCA infarction (Cho et al. 2003; Kiphuth et al. 2010; Walz et al. 2002). Some neurosurgeons do not prefer to treat malignant MCA infarction surgically because of concerns about the post-operative quality of life (Weil et al. 2011). There is a lot of controversy in this issue. While some studies have shown that nearly half of patients had good outcome after surgery with GOS scores of 4 and 5 (Mattos et al. 2010; Mori et al. 2004), some others have reported that surgery could not achieve significant good results (Staykov \& Gupta 2011; van der Worp \& Kappelle 2011). This will increase the number of severely disabled patients, imposing significant pressure over the family and the whole society (Hofmeijer et al. 2009; Schneck \& Origitano 2006).

Analysis of our data showed that near $30 \%$ of patients in the surgical group had good outcome, i.e. GOS scores of 4 and 5; however, respective rate was only $3.3 \%$ in the nonsurgical group. Also, $40 \%$ of patients in the DC group and $83 \%$ in the control group developed poor outcome (GOS scores of 1 and 2). This means that DC not only decreased mortality but also improved outcome.

Review of literature shows that early surgery (during 24 hours from onset of stroke) has had very good result in all ages especially in younger patients (Koh et al. 2000; Pillai et al. 2007); while surgery later than 48 hours may not benefit patients (Antuña-Ramos et al. 2009; Cho et al. 2003; Chen et al. 2007; HernándezMedrano et al. 2012; Hofmeijer et al. 2009; Khatri et al. 2008; Schwab et al. 1998; Vahedi et al. 2007; Zhao et al. 2012). We also operated our patients at an early stage (earlier than 48 hours), and therefore, the observed efficacy of DC in our series is perhaps due to this early intervention.

Age is also another influencing factor. Some studies have shown that patients older than 60 had MRS scores of 4 and greater; while patients younger than 60 showed MRS scores of 3 or lower following decompressive hemicraniectomy (Chen et al. 2007; Foerch et al. 2004; Vahedi et al. 2007; Yang et al. 2005). In this study, we did not include patients

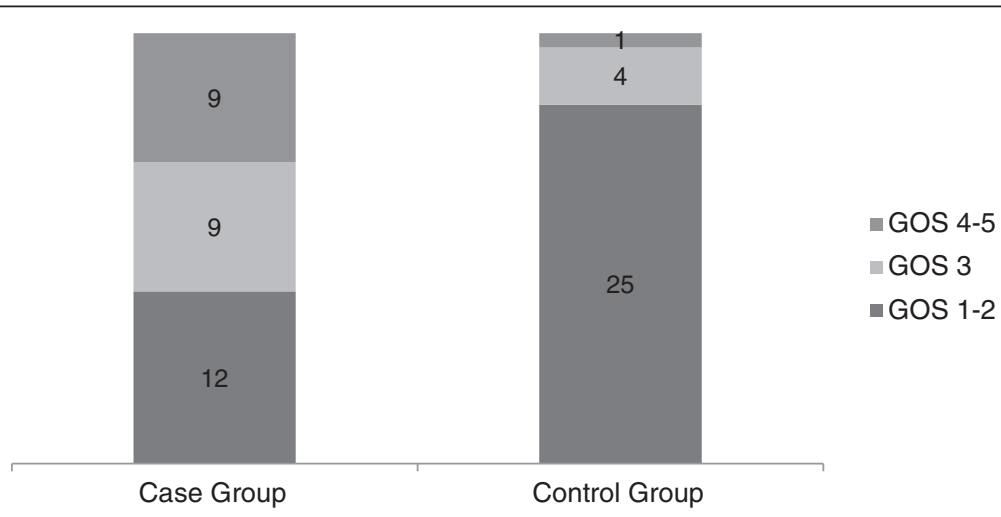

Figure 1 Outcome at 3 months follow-up based on GOS scale. 


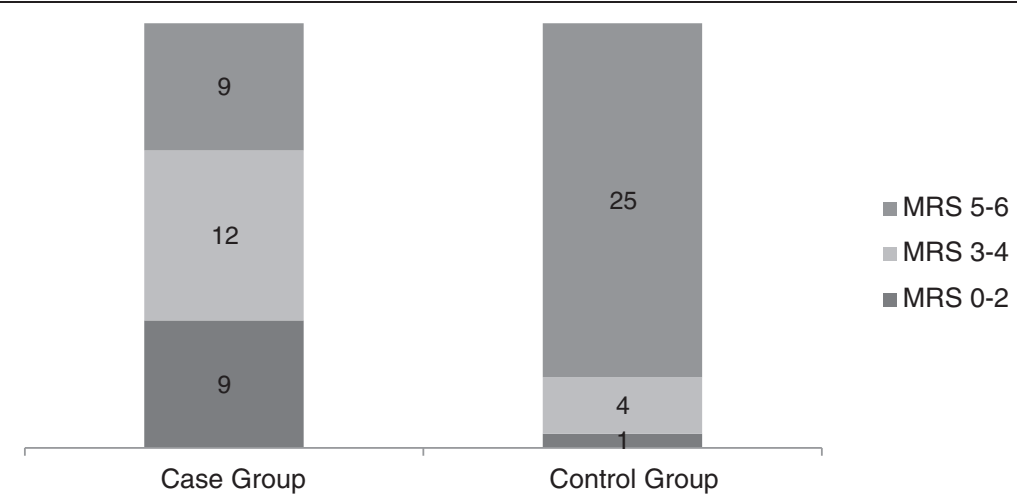

Figure 2 Outcome at three months follow-up based on MRS scale.

older than 80 , and also could not find any differences between the age groups.

The only problem remains in patients with GOS scores of 3 (MRS of 3 and 4), namely severely disabled patients, which were more frequent in the surgical group (30\% versus 13\%; respectively). This means that although surgery improved the whole outcome significantly (an average of 1 scores on the GOS and 2 scores on MRS scales) and decreased mortality, survived patients are still in high risk to be severely disabled. Whether this survival is of any benefit to the patients' families or the whole society is a controversy (Carandang \& Krieger 2008; Holtkamp et al. 2001; Kiphuth et al. 2010; Weil et al. 2011). This problem may be considered as a costeffectiveness issue by health policy makers, or may be presented to the family of any individual patient for decision making. One family may consider even a $1 \%$ chance of survival very valuable, while the other one may not accept the continuous expensive care of a severely disabled patient with nearly any chance of improvement. Therefore, consideration of surgical treatment for every patient requires careful consultation with the family members (Hofmeijer et al. 2009; Schneck \& Origitano 2006).

A major limitation of the study is the lack of randomization and control of samples. The previouslypublished beneficial data on effectiveness of DC on mortality (Delgado-López et al. 2004; Kakuk et al. 2002; Mellado et al. 2005; Mori et al. 2001; Raffelsieper et al. 2002; Robertson et al. 2004; Swiat et al. 2010; Ziai et al. 2003) have made the performance of randomized trials impossible. Our data may provide at most level 2 evidence on the benefits of DC; while longer follow-ups may yield more beneficial data.

\section{Conclusion}

Early DC, performed within 48 hours after presentation and on patients younger than 80 , could reduce mortality and improve outcome significantly in unilateral malignant MCA infarction. We recommend performing the procedure for every eligible patient after careful consultation with the family members.

\section{Consent}

Written informed consent was obtained from all patients for the publication of this report and any accompanying images.

\section{Competing interests}

The authors declare that they have no competing interests.

\section{Authors' contributions}

$A K, B S, A R, P P$ and EAA designed and performed the study. AR drafted the manuscript. JK and $\mathrm{JH}$ helped in the design of the study and interpretation of the data and evaluating the final manuscript. All authors read and approved the final manuscript.

\section{Disclosure}

The authors report no conflict of interest concerning the materials and methods used in this study or the findings specified in this paper.

\section{Author details}

${ }^{1}$ Department of Neurosurgery, Shiraz University of Medical Sciences, Nemazee Hospital, P.O. Box: 71937-11351, Shiraz, Iran. ${ }^{2}$ Shiraz Neuroscience Research Center, Shiraz University of Medical Sciences, Shiraz, Iran.

${ }^{3}$ Department of Neurology, Shiraz University of Medical Sciences, Shiraz, Iran. ${ }^{4}$ Department of Neurosurgery, Helsinki University Central Hospital,

Topeliuksenkatu 5, 00260 Helsinki, Finland.

Received: 16 September 2013 Accepted: 13 January 2014

Published: 28 February 2014

\section{References}

Aarabi B, Hesdorffer DC, Ahn ES, Aresco C, Scalea TM, Eisenberg HM (2006) Outcome following decompressive craniectomy for malignant swelling due to severe head injury. J Neurosurg 104(4):469-479

Antuña-Ramos A, Alvarez-Vega MA, Seijo-Fernández F, Calleja-Puerta S, González-Delgado M, Torres-Campa JM, Gutiérrez-Morales J (2009) Surgical treatment of the stroke in the middle cerebral artery. Rev Neurol 49(7):354-358

Arac A, Blanchard V, Lee M, Steinberg GK (2009) Assessment of outcome following decompressive craniectomy for malignant middle cerebral artery infarction in patients older than 60 years of age. Neurosurg Focus 26(6):E3

Carandang RA, Krieger DW (2008) Decompressive hemicraniectomy and durotomy for malignant middle cerebral artery infarction. Neurocrit Care 8(2):286-289

Chen CC, Cho DY, Tsai SC (2007) Outcome and prognostic factors of decompressive hemicraniectomy in malignant middle cerebral artery infarction. J Chin Med Assoc 70(2):56-60

Cho DY, Chen TC, Lee HC (2003) Ultra-early decompressive craniectomy for malignant middle cerebral artery infarction. Surg Neurol 60(3):227-232 
Delgado-López P, Mateo-Sierra O, García-Leal R, Agustín-Gutiérrez F, FernándezCarballal C, Carrillo-Yagüe R (2004) Decompressive craniectomy in malignant infarction of the middle cerebral artery. Neurocirugia (Astur) 15(1):43-55

Foerch C, Lang JM, Krause J, Raabe A, Sitzer M, Seifert V, Steinmetz H, Kessler KR (2004) Functional impairment, disability, and quality of life outcome after decompressive hemicraniectomy in malignant middle cerebral artery infarction. J Neurosurg 101(2):248-254

Hernández-Medrano I, Matute MC, Abreu F, Masjuán J, Rodríguez V, Martínez-San Millán J, Guillán M, de Felipe A, Medina D, Alonso de Leciñana-Cases M (2012) Decompressive craniectomy in malignant middle cerebral artery infarction. Experience after the implementation of a response protocol. Rev Neurol 54(10):593-600

Hofmeijer J, Kappelle L, Algra A, Amelink GJ, van Gijn J, Van Der Worp HB (2009) HAMLET investigators. Surgical decompression for space-occupying cerebral infarction (the Hemicraniectomy After Middle Cerebral Artery infarction with Life-threatening Edema Trial [HAMLET]): a multicentre, open, randomised trial. Lancet Neurol 8(4):322, 26-33

Holtkamp M, Buchheim K, Unterberg A, Hoffmann O, Schielke E, Weber JR (2001) Hemicraniectomy in elderly patients with space occupying media infarction: improved survival but poor functional outcome. J Neurol Neurosurg Psych 70:226-228

Jüttler E, Bösel J, Amiri H, Schiller P, Limprecht R, Hacke W, Unterberg A, DESTINY II Study Group (2011) DESTINY II: Decompressive Surgery for the Treatment of malignant INfarction of the middle cerebral artery II. Int J Stroke 6(1):79-86

Jüttler E, Schwab S, Schmiedek P, Unterberg A, Hennerici M, Woitzik J, Witte S, Jenetzky E, Hacke W, DESTINY Study Group (2007) Decompressive Surgery for the Treatment of Malignant Infarction of the Middle Cerebral Artery (DESTINY): a randomized, controlled trial. Stroke 38(9):2518-2525

Kakuk I, Major O, Gubucz I, Nyáry I, Nagy Z (2002) New methods of intensive therapy in stroke: hemicraniectomy in patients with complete middle cerebral artery infarction and treatment of intracerebral and intraventricular hemorrhage with urokinase. Ideggyogy Sz 20(3-4):118-127, 55:118-27 (abstract)

Khatri IA, Siddiqui M, Khan I, Nadeem M, Ahmad A (2008) Salvage decompressive craniectomy in malignant MCA infarcts - results of local experience at Shifa International Hospital, Islamabad Pakistan. J Pak Med Assoc 58(7):404-408

Kiphuth IC, Köhrmann M, Lichy C, Schwab S, Huttner HB (2010) Hemicraniectomy for malignant middle cerebral artery infarction: retrospective consent to decompressive surgery depends on functional long-term outcome. Neurocrit Care 13(3):380-384

Koh MS, Goh KY, Tung MY, Chan C (2000) Is decompressive craniectomy for acute cerebral infarction of any benefit? Surg Neurol 53(3):225-230

Mattos JP, Joaquim AF, Almeida JP, Albuquerque LA, Silva EG, Marenco HA, Oliveira Ed (2010) Decompressive craniectomy in massivecerebral infarction. Arq Neuropsiquiatr 68(3):339-345

Mellado TP, Castillo FL, Campos PM, Bugedo TG, Dougnac LA, Andresen HM (2005) Decompressive hemicraniectomy for malignant middle cerebral artery infarction. Report of two cases Rev Med Chil 133(4):447-452

Molina CA, Selim MH (2011) Decompressive hemicraniectomy in elderly patients with malignant hemispheric infarction: open questions remain beyond DESTINY. Stroke 42(3):847-848

Mori K, Aoki A, Yamamoto T, Horinaka N, Maeda M (2001) Aggressive decompressive surgery in patients with massive hemispheric embolic cerebral infarction associated with severe brain swelling. Acta Neurochir (Wien) 143(5):483-491

Mori K, Nakao Y, Yamamoto T, Maeda M (2004) Early external decompressive craniectomy with duroplasty improves functional recovery in patients with massive hemispheric embolic infarction: timing and indication of decompressive surgery for malignant cerebral infarction. Surg Neurol 62(5):420-429

Pillai A, Menon SK, Kumar S, Rajeev K, Kumar A, Panikar D (2007) Decompressive hemicraniectomy in malignant middle cerebral artery infarction: an analysis of long-term outcome and factors in patient selection. J Neurosurg 106(1):59-65

Quinn TJ, Dawson J, Walters MR, Lees KR (2009) Reliability of the modified Rankin Scale: a systematic review. Stroke 40:3393-3395

Raffelsieper B, Merten C, Mennel HD, Hedde HP, Menzel J, Bewermeyer H (2002) Decompressive craniectomy for severe intracranial hypertension due to cerebral infarction or meningoencephalitis. Anasthesiol Intensivmed Notfallmed Schmerzther 37(3):157-162, abstract

Robertson SC, Lennarson P, Hasan DM, Traynelis VC (2004) Clinical course and surgical management of massive cerebral infarction. Neurosurgery 55(1):55-61
Schneck MJ, Origitano TC (2006) Hemicraniectomy and durotomy for malignant middle cerebral artery infarction. Neurol Clin 24(4):715-727

Schwab S, Steiner T, Aschoff A, Schwarz S, Steiner HH, Jansen O, Hacke W (1998) Earlyhemicraniectomy in patients with completemiddle cerebral artery infarction. Stroke 29(9):1888-1893

Spagnuolo E, Costa G, Calvo A, Johnston E, Tarigo A (2004) Decompressive craniectomy in head injury. Intractable ICP. Neurocirugia (Astur) 15(1):36-42

Staykov D, Gupta R (2011) Hemicraniectomy in malignant middle cerebral artery infarction. Stroke 42(2):513-516

Swiat M, Targosz-Gajniak M, Arkuszewski M, Wojtacha M, Bazowski P, Opala G, Pieta M, Gamrot J (2010) Decompressive hemicraniectomy in ischaemic stroke. Neurol Neurochir Pol 44(2):131-138

Vahedi K, Hofmeijer J, Juettler E, Vicaut E, George B, Algra A, Amelink GJ, Schmiedeck P, Schwab S, Rothwell PM, Bousser MG, van der Worp HB, Hacke W (2007) DECIMAL, DESTINY, and HAMLET investigators: Earlydecompressivesurgery in malignantinfarction of the middle cerebral artery: a pooled analysis of three randomised controlled trials. Lancet Neurol 6(3):215-222

Walcott BP, Kuklina EV, Nahed BV, George MG, Kahle KT, Simard JM (2011) Craniectomy for malignant cerebral infarction: prevalence and outcomes in US hospitals. PLoS One 6(12):e29193

Walz B, Zimmermann C, Böttger S, Haberl RL (2002) Prognosis of patients after hemicraniectomy in malignant middle cerebral artery infarction. J Neurol 249(9):1183-1190

Weil AG, Rahme R, Moumdjian R, Bouthillier A, Bojanowski MW (2011) Quality of life following hemicraniectomy for malignant MCA territory infarction. Can J Neurol Sci 38(3):434-438

van der Worp HB, Kappelle LJ (2011) Early decompressive hemicraniectomy in older patients with nondominant hemispheric infarction does not improve outcome. Stroke 42(3):845-846

Yang XF, Yao Y, Hu WW, Li G, Xu JF, Zhao XQ, Liu WG (2005) Is decompressivecraniectomy for malignantmiddle cerebral artery infarction of any worth? J Zhejiang Univ Sci B 6(7):644-649

Zhao J, Su YY, Zhang Y, Zhang YZ, Zhao R, Wang L (2012) Decompressive Hemicraniectomy in Malignant Middle Cerebral Artery Infarct: A Randomized Controlled Trial Enrolling Patients up to 80 Years Old. Neurocrit Care 17(2):161-171

Ziai WC, Port JD, Cowan JA, Garonzik IM, Bhardwaj A, Rigamonti D (2003) Decompressive craniectomy for intractable cerebral edema: experience of a single center. J Neurosurg Anesthesiol 15(1):25-32

\section{doi:10.1186/2193-1801-3-115}

Cite this article as: Rahmanian et al:: Outcome of decompressive craniectomy in comparison to nonsurgical treatment in patients with malignant MCA infarction. SpringerPlus 2014 3:115.

\section{Submit your manuscript to a SpringerOpen ${ }^{\odot}$ journal and benefit from:}

- Convenient online submission

- Rigorous peer review

- Immediate publication on acceptance

- Open access: articles freely available online

- High visibility within the field

- Retaining the copyright to your article

Submit your next manuscript at springeropen.com 